\title{
ENFERMEIROS QUE DEIXARAM DE EXERCER A ENFERMAGEM: POR QUE?
}

\author{
Victória Secaf * \\ Antonia Regina Furegato Rodrigues**
}

SECAF, V.; RODRIGUES, A.R.F. Enfermeiros que deixaram de exercer a enfermagem: por que?. Rev.latinoam.enfermagem, Ribeirão Preto, v. 6, n. 2, p. 5-11, abril 1998.

A evasão profissional dos enfermeiros nos preocupa pois houve um investimento do Estado, da familia e do próprio indivíduo e há carência de enfermeiros no mercado de trabalho. Coletamos, em amostra intencional, a opinião de enfermeiros sobre os motivos que os levaram a deixar de exercer a enfermagem, sobre os conhecimentos de enfermagem que utilizam em sua atual atividade e suas sugestões para evitar a evasão. Nas respostas obtidas verificamos que a evasão do enfermeiro está baseada em um conjunto de circunstâncias desde as estritamente pessoais e de sua formação até as decorrentes da estrutura social e política.

UNITERMOS: evasão profissional, enfermagem, mercado de trabalho, aderência à enfermagem

\section{INTRODUÇÃO}

O quantitativo anual de graduandos das Escolas de Enfermagem (EE's) revela que o Brasil poderia contar com um contingente significativo de profissionais no mercado de trabalho, visto que há mais de cem Escolas de Enfermagem no país.

Pelo cadastro do Conselho Federal de Enfermagem (COFEN), constata-se a existência de mais de 65.000 enfermeiros na ativa (BRASIL. COFEN, 1995).

É de se supor que desse total de profissionais muitos estão exercendo a enfermagem em diferentes especialidades da assistência direta, outros em gerenciamento de unidades em instituições de saúde, outros na docência em escolas/cursos e, outros ainda em atividades indiretas.

Da cota de graduados pelas EE's, além dos já falecidos, dos aposentados e mesmo daqueles que estão fora do país, há também um total de não exercentes da profissão, que se ocupam apenas de atividades no lar (porque a maioria é do sexo feminino). Há, no entanto, um pequeno contingente formado por aqueles que não exercem enfermagem mas estão atuando em outra área. É a chamada evasão profissional e que ocorre em todas as profissões, podendo ser considerado um fato problemático pois reduz o contingente de enfermeiros para atender às necessidades de saúde da população brasileira. Além disso, há grande diversidade de possibilidades de trabalho para este profissional na área de saúde.

A evasão escolar também é assunto polêmico e em algumas publicações encontramos referência especificamente ao seguimento de alunos de cursos como Medicina (GONÇALVES, 1986) e Nutrição (BOOG et al., 1988). Quanto ao seguimento de alunos de graduação em medicina, enfermagem e nutrição encontramos as de IDE et al. (1985) e OGASAWARA \& PAVARINI (1994). O seguimento dos egressos de Escolas de Enfermagem também tem sido objeto de estudo de mestrandos como THOMÉ (1991) tendo registrado que, para mais de 50\% dos entrevistados, a enfermagem foi a $2^{\mathrm{a}}$ opção no vestibular, porém mais de $60 \%$ deles faria enfermagem novamente, se tivesse que optar.

A opção é favorável durante o curso e mesmo depois de graduados. Então, o que acontece com aquelas que deixaram a enfermagem e procuraram outras atividades?

No levantamento de Recursos e Necessidades da Enfermagem, realizado em 1956/1959 há um capítulo sobre os enfermeiros inativos e, do total obtido, há registro de um contingente que exerce outras "ocupações" como magistério, funções burocráticas, comércio, medicina, vida religiosa, e aqueles que se dedicam apenas aos trabalhos no lar (ABEn, 1980).

Na década de 90, nossa inquietação sobre aqueles graduados em enfermagem que deixaram de exercer a

\footnotetext{
* Professora Doutora da Escola de Enfermagem da Universidade de São Paulo

** Doutora em Enfermagem. Professor Associado na Escola de Enfermagem de Ribeirão Preto da Universidade de São Paulo
} 
profissão é fundamentada na carência de enfermeiros no mercado de trabalho, em todo território nacional, e porque a formação de cada um representa um investimento do Estado (quando ele foi aluno de escola governamental) ou da família e do próprio indivíduo.

Um levantamento aleatório dos motivos para esta evasão dos profissionais indicaria que, na maioria das vezes, as causas poderiam ser de origem externa ao principal envolvido isto é, a questão salarial, as oportunidades do mercado de trabalho e/ou até questões sociais.

Estas razões poderiam ser aplicadas a todos, porém, grande número deles permanece na profissão e alguns buscam outros caminhos que são ramificações da própria profissão tais como: laboratórios de análise, empresa de produtos médico-hospitalares e outros.

Mas, outros enfermeiros (que são o objeto de nosso estudo) estão exercendo atividades diferentes daquelas para as quais foram formados. Não encontramos estudos publicados nos quais esses "excluídos da enfermagem" tenham manifestado as razões da evasão, sob a ótica da sua motivação pessoal.

É importante ressaltar que, apesar de não possuirmos dados atualizados do quantitativo de enfermeiros que não exercem a profissão, levantamos a questão para propiciar reflexão, porque a evasão representa, de alguma forma, um investimento "perdido".

A situação se configura merecedora dessa reflexão porque muitas vezes o Estado custeou a formação de pessoas que estão em fase produtiva e que não devolvem esse trabalho específico para a sociedade. Caso essas pessoas tenham estudado em Escolas particulares, alguém investiu na sua formação, o que também se caracteriza como perda desse investimento.

É difícil quantificarmos investimento além do que, este não é foco de nossa preocupação, no momento. Entretanto, a reflexão que ora deflagramos poderá dar início a outros estudos tanto da entrada de estudantes no curso, como durante a graduação e no mercado de trabalho.

Dentre os estudos sociológicos das profissões não é comum que a enfermagem seja comentada. Por esta razão, merece destaque a análise feita por Davis apud DUBAR (1991) em que são relacionadas as seis etapas de "conversão" das pessoas comuns em enfermeiras. Este processo passa pela inocência inicial, pela consciência de que a profissão não é bem o que esperava, pela alienação de si e aceitação de uma dualidade até a interiorização estável quando assume o papel profissional, reforçado pela convivência com os profissionais.

Percebendo a ocorrência da evasão e a falta de estudos a partir de depoimentos dos enfermeiros nesta situação, estamos dando o primeiro passo nesta busca, em nosso meio.

\section{OBJETIVOS}

- Conhecer os motivos expressos pelos enfermeiros a respeito de ter deixado de exercer a enfermagem.

- Identificar elos entre as atividades atualmente exercidas pelos evadidos e sua formação/atuação como enfermeiro. - Analisar a percepção/imagem que têm da profissão e do profissional.

\section{CONSIDERAÇÕES METODOLÓGICAS}

Para conhecer os motivos que levaram enfermeiros a abraçarem outra profissão, foi necessário: a) procurar saber onde estão estas pessoas (enfermeirosfonte dos dados) e b) elaborar um instrumento que nos permitisse obter estas informações (questionário). A pesquisa qualitativa foi o caminho metodológico adequado que encontramos para esta investigação.

\subsection{POPULAÇ̃̃O E AMOSTRA}

Como docentes de duas Escolas de Enfermagem da rede oficial do Estado de São Paulo, conhecemos vários ex-alunos que não exercem a profissão. $O$ Estado de São Paulo possui um dos melhores mercados de trabalho para enfermeiros, mas ao mesmo tempo, oferece muitas outras oportunidades de trabalho à quem tenha formação superior. Entretanto, devido ao nosso contato constante com enfermeiros das Escolas do país, por conta dos cursos de Pós-Graduação que oferecemos nesta área, percebemos que o problema não se restringe às Unidades onde exercemos nossas atividades.

Dessa forma, após uma fase exploratória em que as discussões variaram desde questões de representatividade, de delimitação por Escolas formadoras, de busca por via formal nas secretarias das Escolas, até as questões do objeto mesmo do estudo, decidimos que não nos interessa o número de evadidos ou sua origem, mas, o motivo pelo qual eles deixaram de trabalhar na enfermagem. Foi ainda difícil delimitar o campo de investigação, tanto no tempo como no espaço.

Como nosso objetivo não é fazer uma investigação conclusiva, nem exaustiva, optamos por obter uma amostra intencional e, tal como numa observação espontânea, oferecemos através da análise dos dados obtidos, elementos para futuros estudos do problema (NOGUEIRA, 1964). Este tipo de amostra evolve um pequeno número de pessoas que são escolhidas intencionalmente em função da relevância de seus depoimentos (THIOLLENT, 1988, p.62).

Enfatizamos os aspectos qualitativos dos dados. Se tivéssemos apenas a hipótese de que os enfermeiros 
vão procurar outra profissão por questões econômicas, talvez fosse melhor buscar respostas quantitativamente representativas.

Segundo BARDIN (1991, p.97), uma amostra é rigorosa se for parte representativa do universo total e seus resultados puderem ser generalizados. Nesse sentido, não tem relevância a representatividade da amostra deste estudo mas o conteúdo dela emanado. Entretanto, por ser inédito, poderá ser confrontado posteriormente com outras hipóteses e com a realidade concreta, em outras formas de captá-la.

\subsection{O INSTRUMENTO DE COLETA DE DADOS}

Antes da elaboração do instrumento foi necessário que tomássemos algumas decisões sobre as facilidades e as dificuldades de acesso à população, o conteúdo a ser obtido dos sujeitos e, a forma dada ao instrumento para abordar estes sujeitos.

Optamos pela utilização do questionário devido à dispersão dos sujeitos e à possibilidade de cada um expressar-se por escrito à respeito das questões propostas, sem interferência dos pesquisadores. Consideramos ainda, o baixo custo, a rapidez na obtenção dos dados e, a garantia do sigilo.

As questões aqui condensadas são dirigidas ao objetivo do estudo, e estão divididas em três partes: A Especificação da atividade que exerce atualmente e outras que já exerceu; Informações sobre onde se formou e outros cursos freqüentados; B - Relato sobre os motivos que o levaram a deixar de exercer a enfermagem; Conhecimentos de sua formação como enfermeiro que o ajudam na atual atividade; $\mathrm{C}$ - Sugestões sobre como evitar a evasão do enfermeiro de sua profissão.

As perguntas, são simples, objetivas e interligadas para melhor atender ao questionamento deste estudo e dizem respeito à realidade vivida pelos sujeitos.

Além do questionário, há uma carta explicativa na qual solicitamos a colaboração e garantimos o anonimato dos depoimentos e o devido envelope selado para a resposta.

\section{APRESENTAÇÃO E ANÁLISE DOS RESULTADOS}

Elegemos a abordagem qualitativa para a análise dos dados, não excluindo as informações quantitativas no conteúdo. Segundo BARDIN (1991, p.42), a análise de conteúdo pode ser definida como "um conjunto de técnicas de análise da comunicação visando obter, por procedimentos sistemáticos e objetivos de descrição do conteúdo das mensagens, indicadores (qualitativos ou não) que permitem a inferência de conhecimentos relativos às condições de produção/recepção destas mensagens".

Os dados são tratados a partir de uma análise temática, através da qual os elementos do texto são classificados num sistema de categorias definidas, após leitura e releitura dos dados contidos nas respostas dos informantes.

O tema é composto por unidades e a análise temática segue as fases de pré-análise, exploração do material e tratamento dos resultados obtidosinterpretação (MINAYO, 1993, p.208-211).

O questionário foi encaminhado para 54 enfermeiros dos quais obtivemos 18 respostas de sujeitos formados entre 1972 e 1988 nas seguintes Escolas: cinco da EERP-USP, cinco da EEUSP, dois da PUC-Campinas, um da UNESP-São Carlos, uma da Don DomênicoGuarujá, um de Itajubá, um da UNIFESP-Paulista, um da Unicamp e um da Barão de Mauá-Ribeirão Preto.

Todos trabalharam anteriormente na Enfermagem, exceto uma que já trabalhava numa empresa bancária, enquanto aluna. Preferiu permanecer neste trabalho pelo salário oferecido e porque teve dificuldade em arranjar emprego, como enfermeira, por ser recémformada e sem experiência.

Os demais (17) trabalharam inicialmente como enfermeiros variando esse período de 18 meses até 17 anos. Quase todos exerceram atividades hospitalares, sendo que seis tiveram experiência como docentes de enfermagem. Apenas um profissional revelou experiência unicamente ambulatorial e outro em instituições de atendimento à criança carente.

A maioria desses enfermeiros buscou ampliar seus conhecimentos, através de cursos de Habilitação, de Extensão, de Licenciatura ou de Especialização nas seguintes áreas: dois em Enfermagem do trabalho, um em Saúde Publica, um em Administração Hospitalar e outro em Enfermagem Médico-cirúrgica. Há quem tenha completado outros cursos universitários, tais como: Direito (três), Administração de Empresas (três), Pedagogia (um) e Educação Física (um) e, outros cursos como Informática, Inglês, Homeopatia, Psicodrama e Shiatzu.

Atualmente, esses enfermeiros estão fora da enfermagem, e de acordo com suas informações, pudemos agrupá-los em 2 categorias:

a) Aqueles que exercem atividades como empregados: Fiscal de Tributos do Governo; Gerente Comercial, em empresas; Bancário; Coordenador de Curso em Escola técnica de $2^{\text {a }} \mathrm{Grau}$; Advogada, coordenadora de departamento em autarquia.

b) Aqueles que exercem atividades autônomas: Decorador/paisagista; Diretor Administrativo, em sua indústria; Sócio em uma fábrica; Administrador de 
indústria; Empresários: de um em colégio de primeiro grau, de natação, em clínica veterinária, em lojas de diferentes produtos, em panificadora e em autopeças. São, portanto, alguns administrando suas indústrias e, os outros, administrando algum tipo de comércio próprio.

Analisando o conteúdo das respostas desses enfermeiros sobre sua evasão da profissão, foi possível obter as seguintes categorias temáticas:

\subsection{Motivos da evasão}

O Núcleo de Apoio aos Estudos de Graduação (NAEG) (Universidade de São Paulo, 1995) realizou um Programa de Estudos sobre o destino ocupacional dos ex-alunos da USP (apoiado pela FUVEST) e, apresentou recentemente uma versão preliminar do perfil dos ex-alunos do Curso de Enfermagem de Ribeirão Preto. Verificou que da sua amostra de egressos (formados em 1980-1985-1990), 8\% não exerce qualquer atividade profissional e $8 \%$ está trabalhando fora da área.

Os motivos mais fortes apontados pelo grupo NAEG dos que não estão atuando ou que estão atuando fora da área, foram: baixa remuneração $(20 \%)$, melhores oportunidades fora da área $(20 \%)$ e problemas familiares (15\%) (USP. NAEG, 1995).

Sabemos que, em outras profissões, a evasão também acontece e é motivo de reportagem***, por

\section{Falta na Enfermagem}

- remuneração adequada

- prestígio/reconhecimento

- liberdade para desenvolver seu trabalho

- espirito de equipe/união da classe

- condições de trabalho (pessoais e de infra-estrutura)

- perspectivas futuras

- estímulo ao aperfeiçoamento/crescimento

- contato com o paciente

- retorno profissional

- habilidade técnica (pelo afastamento de exercício dessas atividades)

Percebe-se que estes são fatores intrínsecos da profissão, ou seja, o maior problema parece estar na organização social do trabalho do enfermeiro e, muitas das mudanças necessárias extrapolam a vontade pessoal ou política da enfermagem.

Entretanto, temos que considerar os fatores externos ou situacionais que concretamente competem com as possibilidades do enfermeiro continuar exercendo sua profissão. exemplo sobre um médico que abandonou a profissão e tem uma indústria de mochilas, pois "além de achar que não tinha dom para a medicina, as mochilas começaram a dar dinheiro".

Em geral, os estudos de egressos e/ou evadidos de suas profissões, mesmo naquelas altamente concorridas e com possibilidade de realização econômico/ financeira, mostram que há quem as abandone à procura de algo que lhes dê algum outro tipo de satisfação.

Por outro lado, esses estudos acabam mostrando que o problema econômico não é a mola propulsora para o abandono. No estudo do NAEG (USP. NAEG, 1995) vemos que, embora $58,8 \%$ dos enfermeiros estejam insatisfeitos financeiramente, continuam a exercer sua profissão. Não dá para saber se são os mesmos sujeitos, entretanto $55,4 \%$ têm opiniões positivas à respeito do seu trabalho atual.

Em reportagem sobre profissões****, há uma enfermeira que não está exercendo a profissão por não ter conseguido conciliar os plantões hospitalares com os afazeres da própria família e, de outra enfermeira declarando-se satisfeita com seu trabalho, num Hospital particular na cidade de São Paulo.

Os sujeitos do presente estudo mostraram, nos relatos dos seus motivos para exercer outra profissão, que algumas coisas faltam e outras estão em excesso na enfermagem:

\section{Há em excesso na Enfermagem}

- plantões

- horário de trabalho

- burocracia

- submissão

- impotência

- competitividade entre os enfermeiros

- papéis a desempenhar

- cobrança

- estresse

- oportunidade (herança, convite)

- deixar de ser empregado para ser patrão

- liberdade de horários

- exigências familiares

Alguns sentimentos identificados nos relatos dos enfermeiros complementam a idéia de que a evasão profissional extrapola o problema salarial e passa também por questões muito pessoais. Comparando com as etapas de conversão à profissão de Davis apud DUBAR (1991), 
percebemos que alguns têm pouca identificação com a enfermagem pois desligaram-se em pleno processo de consciência da incongruência entre o que esperava e o que encontrou na profissão. Entretanto, outros tendo atingido a fase de interiorização estável da profissão, desligaram-se impulsionados por algum tipo de contingência mas, continuam a se sentir enfermeiros. Selecionamos algumas falas nos relatos dos sujeitos que expressam os sentimentos correspondentes à estas etapas.

Afeição/identificação "estava feliz com a enfermagem porém..." "não era apaixonada pela profissão..." "ainda sou enfermeira... apenas deixei de trabalhar na enfermagem" "gosto da minha profissão, só que não pude fazer..." "sou enfermeira de coração e empresária de profissão." "eu não gostava da profissão...”.

Revolta “...no sentido mediocre, pois o enfermeiro deixa de ocupar espaços... tem capacidade de fazê-lo... a burocracia emperra as boas idéias..." "...excesso de submissão do corpo de enfermeiros, prejudicando outros colegas...” .

Desanimo/Frustração "Após exercer atividades administrativas percebi que gostava de enfermagem assistencial..." "impossibilidade de evoluir na carreira..." "falta de estímulo..." "... os custos eram pagos do próprio bolso..." "...falta de reconhecimento”.

Descontentamento "...com a atuação dos enfermeiros..." “... se ocupavam menos com o paciente..." "...ter que deixar o filho na creche...".

Solidão/desproteção “... dificuldade de vida normal em cidade grande... cultivar valores próprios de cidade de interior...".

O que salta aos olhos nessa questão dos motivos por estarem os enfermeiros atuando em outras profissões é que, a) não se pode considerar preocupante o índice de evasão em si mesmo; b) não se pode considerar a evasão como algo a ser tratado quantitativamente e c) os motivos alegados por aqueles que não estão exercendo sua profissão sugerem pontos importantíssimos para serem repensados por aqueles que estão exercendo a profissão e por aqueles que têm "poderes" (como na docência, em cargos administrativos e ou políticos) de promover as possíveis melhoras visando aumentar a aderência do enfermeiro à sua profissão.

\subsection{Conhecimentos que utiliza na atual atividade}

A relação entre o conhecimento adquirido na enfermagem e a profissão atual pode ser direta ou indireta, sendo portanto identificada facilmente ou não.

Nessa questão, aparentemente simples, vimos que os sujeitos utilizam desde conhecimentos técnicos e científicos até valores de vida para o cuidado de sua saúde ou das pessoas ao seu redor (em casa ou no trabalho), nas relações interpessoais e nas atividades administrativas que desempenham atualmente.

As opiniões foram espontâneas e podemos observar, nas frases abaixo, que a maioria reconhece a importância de ter feito enfermagem: "Tudo o que aprendi na enfermagem tem muito valor na minha vida pessoal e profissional... só me acrescentou como pessoa”; “...todos da fase de formação e na fase do trabalho foram e são fundamentais"; "Oficialmente, sou a responsável pelo atendimento de enfermagem da empresa-escola..."; "...formadora de opinião nos aspectos afeitos às questões de saúde"; "Acho ótimo ter feito enfermagem, só me acrescentou como pessoa"; "Estágio e trabalho foram importantíssimos para mim"; "Toda experiência profissional (assistência / docência)...

Vários sujeitos disseram que usam muito do relacionamento interpessoal e conhecimentos de administração, porém adequados à situação atual, considerando suas diferenças próprias.

Houve quem negasse, à princípio, que utiliza conhecimentos da enfermagem. Porém, na continuação de seus próprios relatos, encontramos frases como estas: "...lições de vida (valores) que me permitiram e incentivaram a obter sucesso"; "...esclarecer dúvidas e aconselhar funcionários quanto a medicamentos, tipo de doenças, curativos, injeções...” “...procuro orientar no lar, familiares, amigos e funcionários”; “...bagagem que utilizo em todas as minhas atividades pessoal e profissional..."

Finalmente, cabe salientar alguns aspectos que os sujeitos referem ter adquirido na enfermagem e que estão sendo úteis atualmente: "Disciplina - Humanidade - Paciência - Sentido prático, improvisador e organizacional - Lições de disciplina, responsabilidade e dignidade - Lições de vida e de humanidade - Visão diferente de vida - Capacidade de organização - Bom senso, observação e agilidade - Higiene nas atividades do comércio - Auto-disciplina com a própria saúde Técnicas de isolamento - Capacidade de realizar cronogramas de trabalho - Encaminhamento correto de doentes - Coordenação para grupos de pessoas".

\subsection{Sugestões dos enfermeiros para se evitar a evasão}

As reflexões decorrentes das sugestões dos enfermeiros para se evitar a evasão do profissional podem ser destacadas em 4 sub itens:

\section{a) Pessoal}

É muitas vezes citado que a pessoa precisa gostar daquilo que faz. Isto significa ter escolhido uma profissão pela qual tinha interesse, algum tipo de afinidade ou gosto. Significa também ter-se identificado, durante o processo formativo e ter encontrado satisfação no desempenho 
profissional. É também lembrada a necessidade de atenção e esforço pessoal, na busca constante de aprimoramento.

\section{b) Da formação}

É principalmente destacada a importância dos docentes ou seja, que estes gostem do seu trabalho, que busquem atualização e aprimoramento constantes, que tenham orgulho da sua profissão para transmiti-los aos futuros enfermeiros, para que estes sejam mais confiantes, menos submissos e que venham a ocupar o lugar de respeito que lhes é de direito. Sugerem ainda a necessidade de melhor definição do papel do enfermeiro, que os responsáveis pelo ensino, apresentem conteúdos de currículos em consonância com a realidade do trabalho e, que invistam em pesquisa.

\section{c) Dos líderes da enfermagem}

Esperam o incentivo à união e força da classe e a atuação junto às autoridades políticas.

\section{d) Das instituições de saúde}

Estas, recebem a maior carga de sugestões dos enfermeiros representando grande responsabilidade social pelos destinos da profissão. O fator de insatisfação lembrado foi a remuneração incompatível com as responsabilidades que assumem e o desgaste pelo exercício de suas funções. Outra questão muito presente foi a desvalorização profissional, ou seja, o enfermeiro sente falta de reconhecimento do valor do seu trabalho pelos próprios profissionais. Condições de trabalho adequadas também são fatores de retenção do enfermeiro através de distribuição adequada das horas de trabalho, autonomia de atuação, combate ao estresse, possibilidade de crescer dentro da própria instituição e oportunidades de fazer cursos, atualizar-se e reciclar-se.

Segundo os sujeitos desta pesquisa, são necessárias tanto a melhor definição do papel profissional como a possibilidade de uma carreira mais atrativa , para maior retenção dos enfermeiros na profissão. Um deles diz o seguinte "nenhum profissional abre mão de sua atividade se ele estiver satisfeito e reconhecido com aquilo que faz".

PERES (1995) confirma essa idéia mostrando que política de recursos humanos com plano de carreira e outros benefícios facilita e favorece a atração e a retenção dos enfermeiros na organização. Consequência disso, ao nosso ver, poderá ser a diminuição da evasão do enfermeiro na profissão.

\section{CONSIDERAÇÕES FINAIS}

Como percebemos neste estudo, a evasão do enfermeiro para outra atividade profissional não está baseada em um só ponto crítico ou situacional. Há um conjunto de circunstâncias desde o estritamente pessoal, passando pelos meandros de sua formação, da estrutura social do próprio sistema de saúde atual e chegando até aos aspectos políticos. Verificamos também que conforme o momento do desligamento, a reação do enfermeiro vai ser influenciada pela fase de inserção profissional em que se encontrava.

Não podemos, como enfermeiros e docentes ficar de braços cruzados diante desta situação. Precisamos continuar trabalhando para que a sociedade reconheça a necessidade, valorize a competência e a atuação do enfermeiro.

\section{NURSES WHO QUIT NURSING: WHY?}

Professional evasion of nurses is a concern because there was an investment from State, family and from the individual himself and there is a lack of nurses at work field. We have collected, in an intentional sample, the opinion of nurses about the reasons that made them quit nursing, the nursing knowledge they use in their actual activity and their suggestions to avoid evasion. We have checked out according to the answers that nurse's evasion is based on a set of circumstances from strictly personal ones to formal education as well as others resulting from the social and political structure.

KEY WORDS: profissional evasion, nursing, work field, linkage to nursing

\section{ENFERMEROS QUE DEJARON DE EJERCER LA ENFERMERÍA: POR QUÉ?}

El abandono de la carrera entre los enfermeros está causando preocupación, pues hasta la conclusión del curso, han invertido el Estado, la família y el individuo. La gravedad de la situación se acentúa por la escasez de enfermeros ejerciendo la profesión. En una muestra intencional de enfermeros, su opinión sobre los motivos que les inducieron a dejar de practicar la enfermería, y los conocimientos de enfermería que utilizan en el cumplimiento de sus actividades. Se identificaron igualmente, 
las sugerencias que hicieron para evitar la evasión. En las respuestas, verificamos que el abandono está basado en un conjunto de circunstancias desde las estrictamente personales y de la formación hasta las derivadas de la estructura social y política del País.

TÉRMINOS CLAVES: abandono profesional, enfermería, mercado de trabajo, adhesión a la enfermería

\section{REFERÊNCIAS BIBLIOGRÁFICAS}

\section{ASSOCIAÇÃO BRASILEIRA DE ENFERMAGEM.} Relatório final de levantamento de recursos e necessidades de Enfermagem no Brasil: 1956/ 1958. Brasília, 1980.

02. BARDIN, L. Análise de conteúdo. Rio de Janeiro: Edições 70, 1991.

03. BOOG, M.C.I. et al. Situação profissional dos nutricionistas empressos da PUCCAMP: áreas de atuação estabilidade, abandono da profíssão e desemprego. Rev. Nutr. PUCCAMP, v. 1, n.2, p. 139-52, 1988.

04. BRASIL. Conselho Federal de Enfermagem. Normas e notícias. Brasília, 1995.

05. DUBAR, C. La education: constructio des identités sociales et profissionales. Paris: Colin, 1941. p. 145-149.

06. GOLÇALVES, E.L. A terminalidade do curso de graduação em medicina: riscos, problemas e soluções. Rev. Bras. Educ. Méd., v. 10, n. 3, p. 140-7, 1986.

07. IDE, C.A.C. et al. O seguimento de graduação em enfermagem. Rev. Esc. Enfermagem USP, São Paulo, v. 19, n. 3, p.195-211, 1985.

08. MINAYO, M.C.S. O desafio do conhecimento: pesquisa qualitativa em saúde. São Paulo: Hucitec/Abrasco, 1993.
09. NOGUEIRA, O. Pesquisa social: introdução às suas técnicas. São Paulo: Nacional, 1964.

10. OGASAWARA, M.; PAVARINI, S. C. L. Algumas características de cursos de graduação em enfermagem oferecidos em tempo parcial: dado para uma análise de demanda e evasão. Rev. Bras. Enfermagem, v. 47, n. 2, p.134-43, 1994.

11. PERES, H. H. C. Fenômeno recrutamento e seleção de enfermeiros em hospitais: enfoque fenomenológico. São Paulo, 1995. 208 p. Dissertação (Mestrado) - Escola de Enfermagem, Universidade de São Paulo.

12. THIOLLENT, M.C.S. Metodologia da pesquisaação. São Paulo: Cortez, 1988.

13. THOMÉ, E. G. R. O egresso do curso de Enfermagem da UNISINOS e sua situação ocupacional. Porto Alegre, 1991. 159p. Dissertação (Mestrado) - Pontifícia Universidade Católica do Rio Grande do Sul.

14. UNIVERSIDADE DE SÃO PAULO. NAEG. Núcleo de Apoio aos Estudos de Graduação. Perfil dos ex-alunos do curso de enfermagem de Ribeirão Preto: versão preliminar. São Paulo, 1995. (Mimeografado). 